\title{
Etos Kerja Kristen dan Budaya Mapalus sebagai Perberdayaan Ekonomi Gereja di Minahasa
}

\section{Ethos of Christian Work and Mapalus Culture as the Economic Empowerment of the Church in Minahasa}

\author{
Feldy Lolangion* \\ Sosiologi Agama, Fakultas Teologi, Universitas Kristen Satya Wacana, Indonesia \\ Diterima: 19 April 2021; Direview: 02 Mei 2021; Disetujui: 19 Mei 2021
}

\begin{abstract}
Abstrak
Penelitian ini bertujuan untuk memahami dan memberikan solusi dari permasalahan kemiskinan di Daerah Minahasa, terlebih khusus gereja Protestan di Minahasa. Permasalahan yang nampak adalah kurangnya gereja dalam melakukan pemberdayaan ekonomi. Di sisi lain, budaya Mapalus yang menjadi falsafah orang Minahasa sudah mulai tergeser oleh perkembangan zaman. Hal ini membuat peneliti tertarik untuk meneliti tentang Etos Kerja Kristen dan budaya Mapalus sebagai pemberdayaan ekonomi gereja di Minahasa. Dengan menggunakan kajian sosiologi dan ekonomi, peneliti menggunakan teori klasik dari Max Weber tentang The Protestant Etic and Spirit of Capitalism, dan Adam Smith tentang The Wealth of Nations. Untuk menyikapi dan mengkaji permasalahan itu, penelitian ini menggunakan penelitian kualitatif, dengan menggunakan studi kepustakaan. Data dikumpulkan melalui literatur, refrensi, dan artikel yang berhubungan dengan etos kerja Protestan, etos kerja Minahasa, dan semangat kapitalisme. Kapitalisme yang dimaksudkan oleh peneliti adalah kapitalisme yang postitif, dimana kapitalisme yang berjalan lurus dengan etos kerja orang Kristen. Di sisi lain juga Minahasa sebagai lokus penelitian, memiliki etos kerja yang disebut Mapalus. Walaupun terdapat perbedaan antara dua etos kerja tersebut, tetapi kedua-duanya bisa meperkaya pemahaman dan moral dari warga gereja di Minahasa dalam melakukan pemberdayaan ekonomi.

Kata Kunci: Etos Kerja Protestan; Mapalus; Kapitalisme.
\end{abstract}

\begin{abstract}
This study aims to understand and provide solutions to poverty problems in the Minahasa area, especially the Protestant church in Minahasa. The problem that appears is the lack of the church in carrying out economic empowerment. On the other hand, the Mapalus culture which is the philosophy of the Minahasa people has begun to be displaced by the times. This makes researchers interested in researching Christian Work Ethics and Mapalus culture as economic empowerment for the church in Minahasa. By using sociological and economic studies, the researcher uses classic theory from Max Weber about The Protestant Ethic and Spirit of Capitalism, and Adam Smith about The Wealth of Nations. To address and examine this problem, this study uses qualitative research, using literature study. Data were collected through literature, references, and articles related to the Protestant work ethic, the Minahasa work ethic, and the spirit of capitalism. Capitalism that is meant by researchers is positive capitalism, where capitalism is running straight with the work ethic of Christians. On the other hand, Minahasa, as a research locus, has a work ethic called Mapalus. Although there are differences between the two work ethics, both can enrich the understanding and morals of church members in Minahasa in carrying out economic empowerment.

Keywords: Protestant Work Ethic; Mapalus, Capitalism.
\end{abstract}

How to Cite: Lolangion, F., (2021). Etos Kerja Kristen dan Budaya Mapalus sebagai Perberdayaan Ekonomi Gereja di Minahasa. Anthropos: Jurnal Antropologi Sosial dan Budaya (Journal of Social and Cultural Anthropology) 7 (1): 36-44.

${ }^{*}$ Corresponding author:

E-mail:fl02041998@gmail.com
ISSN 2549-166o (Print)

ISSN 2550-1305 (Online) 


\section{PENDAHULUAN}

Di zaman modern saat ini, agama selalu diperhadapkan dan memperdahapkan dirinya dengan politik, sosial, dan ekonomi. Segala aspek itu berkelindang satu sama lain. Agar supaya agama tidak kehilangan eksistensinya, mau tidak mau agama bergerak dan memperhadapkan dirinya dengan politk, sosial, dan ekonomi, sehingga agama bisa menjawab tantagan zaman.

Menurut peneliti, ketika berbicara tentang hubungan antara agama dan ekonomi, banyak perspektif masing-masing individu akan hal itu, dan peneliti membaginya dalam empat perspektif. Pertama, Agama dan Ekonomi tidak dapat disatukan. Beberapa individu memiliki perspektik bahwa, agama bersifat sakral sedangkan ekonomi bersifat profan. Segala sesuatu yang tentang permasalahan ekonomi bukan tanggung jawab agama, atau terlebih khusus gereja, melainkan tanggung jawab dari pemerintah. Perspektif demikianlah yang membuat beberapa gereja kurang memperhatikan permasalahan kemiskinan yang ada di dalam jemaatnya. Kedua, komoditas agama. Beberapa individu memiliki perspektif bahwa agama bisa dijadikan brang dagang utama, di mana unsur-unsur agama bisa dijual demi mendapatkan keuntungan pribadi. Ketiga, ekonomi yang mempengaruhi agama. Salah satu tokoh yang memiliki perspektif yang demikian adalah Karl Marx. Menurut Marx, para pemilik modal yang menguasai ekonomi, bisa memberikan intervensi kepada gereja. Perspektif Marx itu muncul ketika dia menganalisis perbedaan kelas pada masanya. Yang keempat, agama yang mempengaruhi ekonomi. Perspektik yang terakhir inilah yang akan menjadi fokus pengkajian peneliti.

Salah satu tokoh yang memiliki perspektif bahwa agama juga bisa mempengaruhi ekonomi adalah Max Weber. Dia adalah salah satu tokoh sosiolog klasik. Dalam bukunya "Die protestantische
Ethik und der 'Geist' des Kapitalismus" yang dalam bahasa Indonesia, yaitu "Etos Kerja Kristen dan Semangat Kapitalisme" mengstimulus masyarakat Kristen Protestan pada waktu itu untuk dapat menjawab tantangan zaman yang ada yang berhubungan dengan ekonomi.

Minahasa yang menjadi lokus penelitian, memiliki berbagai macam nilai budaya. Minahasa adalah daerah yang memiliki penduduk mayoritas Kristen. Sehingga, masyarakat Minahasa memiliki nilai-nilai Kristiani yang tercampur dengan nilai-nilai budaya Minahasa. Tetapi salah satu nilai budaya Minahasa yang saat ini sudah mulai memudar adalah Mapalus.

Di sisi lain juga, saat ini masyarakat dibeberapa daerah di Minahasa masih sementara menghadapi permasalahan kemiskinan. Dalam hal pengentasan kemiskinan, jika dikaitkan antara agama, budaya dan ekonomi, apakah perspektif Max Weber tentang Etika Protestan yang mempengaruhi ekonomi masih relevan sampai saat ini? Apakah budaya mapalus dapat mengstimulus masyarakat, terlebih khusus gereja dalam pengentasan kemiskinan? Artikel ini akan berusaha untuk menjawab hal tersebut.

\section{METODE PENELITIAN}

Dalam tulisan ini,
menggunakan metode ${ }^{\text {penelitian }}$ kepustakaan. Metode kepustakaan adalah teknik penelitian dengan meneliti kumpulan buku, literatur, dan berbagai tulisan dalam menjawab suatu masalah yang akan diteliti Metode penelitian kepustakaan juga adalah suatu kajian teoritis atau literatur ilmiah yang berhubungan dengan budaya, nilai, dan norma yang ada pada lokus penelitian (Sugiyono: 2012). Peneliti menggunakan pendekatan Ilmu interdipiliner, yaitu pendekatan dengan mengguanakan berbagai ilmu pengetahuan yang saling berkelindang atau relevan. Sehingga penelitian yang bersifat interdisipliner 
memiliki sifat yang sangat kompleks, ganda dan holistis (Kalean, 2012).

\section{HASIL DAN PEMBAHASAN Kapitalisme dan Kapitalisme Zaman Modern}

Adam Smith sebagai salah satu tokoh ekonomi, lewat bukunya: The Wealth of Nations, dijuluki sebagai bapak Kapitalisme. Lewat bukunya itu, dia mengatakan bahwa kapitalisme adalah sebuah sistem ekonomi yang menjadikan kepentingan individu sebagai orientasi awal dalam melakukan pengelolahan ekonomi. Tetapi, orientasi kepentingan individu juga menjadi awal dalam orientasi kepentingan publik atau sosial. Dalam bukunya, Smith mengatakan, dalam mengelolah ekonomi, tiap individulah yang mengetahui kepentingannya masingmasing, sehingga tidap individu dapat memenuhi kepentingannya masingmasing. Hal tersebut bukan bearti bahwa tiap individu mengesampingkan kepentingan bersama, tetapi lewat hal ini, individu dapat memperhatikan kepentingan bersama apabila individu mendapat kesempatan untuk memenuhi, memuaskan, dan mengekspresikan kepentingannya masing-masing tanpa membatasan lapangan produksi. Smith menyinggung tentang "pembatasan lapangan produksi", karena pada konteks waktu itu, negara Inggris yang sangat feodal, membatasi tiap individu untuk mengelolah ekonominya. Lewat pemerintahan yang feodal, hak kepemilikan tanah banyak dimiliki oleh pemerintah, sehingga Smith mendorong tiap individu untuk bebas mengegolah ekonomi, dan bebas untuk melakukan usahanya lewat keterampilan masingmasing.

Karl Marx yang adalah sosiolog klasik yang memandang kapitalisme tidak didefinisikan oleh orientasi kaum kapitalis. Apapun orientasi yang tiap individu sadari, mereka semua didorong oleh logika sistem ekonomi yang mengedepankan pengumpulan modal. Menurut Marx, kapitalisme adalah suatu bentuk masyarakat kelas, di mana manusia diorganisasikan atau dikelompokkan untuk produk si kebutuhan hidup. Salah satu karya terakhir dari Marx adalah Das Capital yang muncul pada tahun 1887. Lewat karyanya itu, dia mengatakan bahwa kapitalisme itu memiliki ciri mutlak yakni borjuis dan eksploitasi (Kristeva, 2015).

Menurut Simon Tormey dalam bukunya "Anti Kapitalisme", mengatakan bahwa Marx adalah seorang pemikir antikapitalisme terbesar, karena dia menatakan dalam suatu kapitalisme ada dua kelas yang saling bertentangan (Tormey, 2016). Oleh sebab itu dalam perspektif Marx, kapitalismelah yang menjadi cikal bakal munculnya pengelompokkan kelas ekonomi, yang mengusai kapitalisme disebut kaum bojuis, dan yang dikuasai dan teralienasi oleh kapialisme disebut kaum proletar.

Sistem kapitalisme mulai muncul pada peralihan zaman feodal ke zaman modern. Kapitalisme sebagai sistem ekonomi, selalu terkait dengan kolonialisme. Karena konteks pada zaman itu akumulasi modal yang berasal dari Eropa lebih khusus dari Inggris didistribusikan ke seluruh dunia, yang menghadirkan kemiskinan di wilayah jajahannya.

Kelahiran kapitalisme dibantu oleh tiga tokoh besar, yaitu Martin Luther yang lebih kepada teologi, Benjamin Franklin yang lebih kepada filsafat, dan Adam Smith yang memberikan dasar-dasar ekonominya. Martin Luther mengemukakan ajarannya, "bahwa manusia menurut kodratnya menjadi suram karena dosanya dan hanya lewat dan karyannya saja yang dapat menyelamatkanya dari kutukan abadi".

Franklin adalah tokoh yang memberi dasar-dasar filosofis, dia mengajak semua orang untuk bekerja keras untuk mengakumulasi modal dan usahanya sendiri, sehingga ia mengamanatkan 
"waktu adala uang". Tokoh yang terakhir yaitu Adam Smith, dia lebih menekankan tentang spirit kapitalismenya dalam sebuah konsep sebagai mekanisme pasar. Ia mengatakan bahwa barang langka membuat barang itu menjadi mahal, sehingga akan semakin sulit di dapatkan apalagi pagi mereka yang berpenghasilan rendah. Tetapi dalam hal ini, menurut Smith, yang harus dilihat adalah perilaku produsen. Ketika harga barang mahal, maka keuntungan produsen akan meningkat. Ketika keuntungan yang dijanjikan itu tinggi, maka ahkirnya banyak produsen yang memproduksinya. Sehingga kelangkaan barang itu yang dulu mahal akan menjadi murah dan akhirnya kebutuhan masyarakat akan terpenuhi (Kristeva, 2015). Sehingga masalah yang terjadi di masyarakat akan diselesaikan oleh kapitalisme. Lewat gagasan atau pemikiran-pemikiran dari ke tiga tokoh tersebut, menjadi dorongan bagi manusia untuk berpegang pada kapitalisme.

Tetapi Menurut Duddley Dillard, model-model ekonomi yang menjadi cikal bakal kapitalisme sudah ada sejak zaman kuno. Menurut Dillard, kapitalisme bukan hanya dipahami ketika muncul ekonomi pada abad ke-19. Tetapi juga menurut Dillard cikal bakal kapitalisme mulai berkembang pada akhir abad pertengahan (Sukirno, 1985). Dillard membagi perkembangannya menjadi tiga tahapan, yaitu kapitalisme awal, kapitalisme klasik, dan kapitalisme lanjut.

Kapitalisme Awal ada pada tahun 1500 sampai tahun 1750. Pada abad pertengahan, Inggris adalah negara yang industri pangannya terbesar di benua Eropa. Karena bahan mentah wool mudah diperoleh di Inggris dan karena adanya pemintalan dan mesin sederhana, sehingga industri di Inggris dapat memantapkan diri sampai pada pendesaan. Meskipun mengalami banyak masalah, industri sandang di pendesaan Inggris terus bertumbuh pesat pada sekitar abad ke-16, abad ke-17, dan abad ke-18. Oleh sebab itu, instri wool melopori kapitalisme sebagai sistem sosial dan ekonomi, juga itu adalah kapitalisme pertama kali yang berakar di Inggris (Dillard, 1987).

Sehingga Kapitalisme pada periode ini masih berfokuskan pada pemenuhan kebutuhan pokok yang ditandai dengan kemunculan industri sandang di Inggris sejak abad ke-14 sampai abad ke-19. Di beberapa wilayah di Inggris pada saat itu industri terus berkembang pesat. Menurut Dillard, kapitalisme pada tahapan ini didukung pada tiga tahapan. Pertama, dukungan agama dengan menanamkan sikap dan karakter kerja keras, serta anjuran untuk hidup hemat. Kedua, hadirnya logam membantu distribusi pendapatan atau upah, laba dan sewa. Ketiga, keikut sertaan negara dalam membantu membentuk modal (Kristeva, 2015).

\section{Semangat Kapitalisme Yang Mendukung Ekonomi Gereja}

Max Weber adalah seorang sosiolog klasik yang legendaris dari Jerman. Ajaranajaran dari Weber sangat mempengaruhi dan menyumbang perkembangan pemikiran sosiologi, seperti analisisnya tentang wewenang, birokrasi, sosiologi agama, organisasi ekonomi dan lainnya (Soekanto, 2009). Tesis Max Weber tentang "The Protestant Ethic and the Spirit of Capitalism" yang ditulis pada 1904 dan 1905, membuka pandangan baru bagi warga jemaat Protestan di Jerman tentang pentingnya memiliki spirit atau semangat kapitalisme bagi pertumbuhan ekonomi jemaat. Dalam konteksnya dia melihat justru banyak pemilik modal atau kaumkaum elit, mereka beragama Protestan. Sedangkan para penganut Katolik memisahkan dirinya dengan kehidupan duniawi dan hanya tinggal di biara-biara. Di sisi lain juga etika Protestan seperti yang dibawa oleh Calvin bisa menjaga kapitalisme agar terus berjalan ke arah positif. Dalam konteks gereja kontemporer, semangat kapitalisme juga sangat 
diperlukan dalam mengelola ekonomi warga gereja.

Karya Weber ini mengritik pemahaman Karl Marx yang memandang bahwa budaya hanya bentuk ekspresi dari tatanan ekonomi (Haryanto, 2015). Sedangkan Weber berpendapat bahwa budaya, dalam hal ini budaya Protestan, yang di dalamnya etika protestan, sangat mempengaruhi ekonomi. Menurut Weber penjelasan tentang budaya juga bisa menjawab permasalahan-permasalahan ekonomi dalam masyarakat, terlebih khusus bagi warga gereja Protestan.

Aktivitas keduniaan mendapat kedudukan yang tinggi dalam agama Protestan, karena lewat pandangan etika Protestan, bahwa hal seperti itu bernilai ibadah. Setiap aktivitas keduniaan yang dilakukan untuk memperoleh perkenaan dari Tuhan, memiliki nilai positif, dan hal tersebut merupakan aktivitas moral yang paling utama (Haryanto, 2015). Seperti yang dijelaskan di atas bahwa etika Protestan berbeda dengan pandangan Katolik. Pada konteks waktu itu, etika Protestan mengatakan bahwa dalam aktivitas kehidupan, manusia harus terlibat dengan kehidupan rasionalitas ekonomi keduniaan. Berbedah dengan pandangan Katolik yang memisahkan diri dengan halhal yang berbau keduniaan.

Weber juga bukan hanya meneliti tentang agama Protestan dan masyarakat Barat, tetapi dia juga meneliti agama-agama besar lainnya yang ada di Asia, seperti Islam, Hindu, Buddha, Konfusianisme dan Yahudi. Dalam penelitiannya dengan agama-agama besar itu, Weber mencoba untuk mengaitkan hubungan antara agama-agama itu dengan ekonomi. Weber mencoba untuk mencarai apakah agama besar lainnya juga memiliki budaya seperti etika Protestan. Akhirnya Weber mendapatkan bahwa setiap agama memiliki etika ekonomi masing-masing. Tetapi yang menjadi pokok permasalahan, apakah etika ekonomi itu direalisasikan dalam kehidupan sehari-hari atau tidak.
Dalam penelitiannya, dia mendapatkan bahwa etika pada agama-agama di Asia hanya sebagai "hiasan dinding", sehingga persoalan ini yang membuat tingkat keberhasilan ekonomi di tiap negara berbeda-beda (Haryanto, 2015). Memang Orang Yahudi terkenal dengan bisnis kuno mereka pada abad pertengahan, walaupun itu sebenarnya watak dari semua pedagang primitif. Namun watak dari orang Yahudi ini pun masih jauh dari ciri kapitalisme modern, dan juga berbedah dengan kapitalisme di era linnya (Weber, 2012).

Weber mengidentifikasikan bahwa Protestan, terlebih khusus Calvinis berperan sebagai akar kapitalisme. Kenapa dikatakan demikian? Karena yang menginisiasi perkembangan ekonomi di Barat waktu itu adalah revolusi agama, salah satu contoh, yaitu tentang relevansi sikap hidup orang menang dianggap kaya dan relevansi orang yang kalah dianggap miskin (Haryanto, 2015).

Menurut Weber, baik Protestanisme maupun Kapitalisme, sama sama memiliki pandangan hidup tentang yang rasional dan sistematis. Etika Protestan membuat para warga gereja menghindari kemalasan dan menekankan tentang hidup rajin dalam melaksanakan tugas dalam kehidupan sehari-hari, terlebih khusus pada kegiatan ekonomi sehari-hari. Hal seperti itu, sama dengan perkembangan kapitalisme modern, di mana kapitalisme menuntut untuk membatasi konsumsi, agar supaya uang yang didapatkan dari hasil keuntungan, bisa diinvestasikan kembali dan untuk pertumbuhan modal. Dalam kapitalisme juga, menuntut individu untuk bekerja secara disiplin dan bekerja secara teratur. Hubungan antara etika Protestan dan Kapitalisme merupakan dua hal yang tidak dapat terpisahkan dan dalam sejarahnya selalu bersifat dialektik, karena di satu sisi etika Protestan membantu pertumbuhan kapitalisme, dan disisi lain kapitalisme yang lebih sekuler.

Dalam konteks Weber, etika Protestan membantu pertumbuhan kapitalisme ke 
arah yang positif, hal itu terjadi sebelum kapitalisme terpengaruh oleh hal-hal sekuler. Hal itu yang membuat kapitalisme yang sejatinya dapat membuat individu bekerja giat dan membangun interaksi dengan individu ata kelompok, menjadi individu yang hanya mementingkan diri sendiri (Johnson, 1986). Menurut Weber, kapitalisme modern adalah hasil dari proses rasionalisasi, yang berakar dari pengaruh historis (Jones, 2009). Oleh sebab itu, etika Protestan membuat tiap individu dalam mengelola ekonomi, lebih memakai pilihan rasional dan melakukan penerapan secara metodologis dalam kehidupan sehari-hari. Bukti tindakan tersebut secara sederhana, yaitu bersifat sederhana, jujur, dan rela berkorban. Dalam pandangan Weber, sikap-sikap seperti itu dapat menghasilkan kekayaan ekonomi privat dan merupakan kebalikan dari ketamakan dan ketidakadilan (Haryanto, 2015).

Dalam hubungannya dengan rasionalisme, seseorang dapat merasionalisasikan kehidupan dari sudut pandang dasar. Rasionalitas menurut Weber, merupakan historis yang meliputi dunia secara keseluruhan. Hal tersebut mendorong kita untuk mendapatkan inti intelektual yang merupakan bentuk konkret dari rasional, di mana ide-ide tentang panggilan dan kesetiaan terhadap pekerjaan tetap tumbuh (Weber, 2015).

Etika dari sekte-sekte pada waktu itu, seperti Calvinisme, Puritanisme, Methodisme, dan gereja-gereja baptis lainnnya, memiliki kesamaan dalam membantu perkembangan ekonomi warga gereja. Dalam etika tersebut, sama-sama berbicara tentang takdir manusia sela mereka masih hidup maupun sudah ada di akhirat, semua ditentukan dari apa yang dia lakukan, baik itu perilakunya atau kerja kerasnya selama dia masih hidup di dunia. Seperti dalam doktrin Calvin, dalam doktrin tersebut mengajarkan bahwa hanya sedikit umat manusia yang di pilih oleh Tuhan, agar supaya di pilih oleh Tuhan, mereka harus bekerja secara sungguh-sungguh.
Apapun profesi dari warga gereja, lewat etika dan doktin seperti itu memunculkan stigma bagi mereka bahwa itu adalah panggilan suci atau dengan istilah calling (Haryanto, 2015). Karena hal tersebut, sehingga mengstimulus warga gereja agar lebih giat bekerja, bukan hanya bekerja untuk memenuhi kebutuhan, tetapi juga bagi mereka itu adalah salah satu misi suci agar mereka bisa menjadi orang pilihan Tuhan.

Kristen Protestan adalah agama mayoritas di Minahasa, dan etika Protestan ini mendukung semangat kapitalisme modern, di mana etos kerja yang secara esensial mendukung etos kerja modern. Dalam etika Protestan, pekerjaan dilakukan untuk mencapai masa depan yang lebih baik. Manusia yang hidup di dunia mempunyai calling untuk menerima tugas dan misi, yakni melakukan kewajiban agama. Calling dapat membuat tujuan hidup menjadi tegas, visi dan misi hidup menjadi jelas. Calling juga menimbulkan keberanian moral, keteguhan hati, dan integritas dalam berkarya, yaitu totalitas yang seimbang antara emosi, pikiran dan jiwa (Sinamo, 2011).

Inti dari tesis Weber ini, dia mengatakan bahwa kapitalisme di dunia Barat dapat berkembang karena disebabkan oleh etika Protestan. Etika Protestan tersebut seperti, kerja keras, jujur, profesional, hemat, dan penuh perhitungan. Dengan berpegang pada etika Protestan tersebut, dapat menyebabkan surplus ekonomi yang diinvestasikan kembali dalam usaha-usaha ekonomi (Haryanto, 2015). Sehingga dengan kata lain, etika Protestan merupakan pereangsang bagi meningkatnya pertumbuhan sistem ekonomi kapitalis (Johson, 1986). Etika Protestan juga dapat mempengaruhi dan "mengontrol" jalannya warga gereja dalam melakukan kapitalisme. Mengontrol agar supaya kapitalisme tidak dilakukan untuk kepentingan diri sendiri, atau menghalalkan berbagai macam cara untuk 
kepentingan sendiri, tetapi dalam kesuksesan tidak mengalienasikan orang lain.

\section{Budaya Mapalus}

Di Indonesia nilai-nilai yang mengandung tentang semangat kapitalisme atau pemberdayaan ekonomi, yang lebih spesifik tentang wirausaha dapat dilihat dari pepatah yang mengatakan: "berakitrakit dahulu, berenang-berenang-renang kemudian". Kalimat ini merupakan falsafah Indonesia. Kenapa? Karena keberhasilan suatu individu selalu diperoleh lewat suatu perjuangan keras. Semangat kapitalismelah yang mendorong individu untuk terus melakukan usaha, walau banyak tantangan dan tidak semudah membalikkan telapak tangan.

Minahasa sebagai lokus penelitian peneliti memiliki falsafah hidup yang mendorong masyarakat minahasa untuk menjadi Tou. Bagi masyarakat Minahasa, Tou adalah bahasa minahasa yang memiliki arti "Manusia". Pengertian manusia yang dipakai masyarakat minahasa, berbeda dengan pegertian umumnya. Ketika salah satu masyarakat sudah disebut Tou, maka dia telah menjadi manusia seutunya, di mana dia telah membangun relasi dengan Tuhan, alam, dan manusia. Bisa dilihat dalam buku Jan Tinggogoi yang berjudul "Tumou Tou: Hidup Menjadi Manusia Sejati".

Beberapa falsafah hidup masyarakat Minahasa yang dikemukakan oleh Richard Siwu (2002), antara lain: a) Masigi-sigian, yang bearti "saling menghormati satu sama lain". b) Masaali, yang bearti "pelayanan, terlebih khusus pelayanan kepada orang tua". c) Marukup, yaitu tentang kebersamaan, di dalamnya berbicara tentang "solidarity dan equality". d) Masuat Peleng/Paumung, yang bearti "musyawarah mufakat" e) Mapalus, yaitu tentang "saling membantu atau gotong royong."

Falsafah hidup Mapalus adalah budaya Minahasa yang berhubungan dengan etos kerja masyarakat Minahasa. Mapalus berawal dari akar kata, dalam bahasa daerah Tombulu, yang merupakan bahasa daerah minahasa, kata mapalus merupakan gabungan dari dua kata yaitu: ma (mak) berarti sedang mengerjakan sesuatu; sedangkan Palus berarti kegiatan bersama untuk kepentingan bersama dan masing-masing anggota secara bergiliran (Turang, 1983). Pengertian mapalus dalam kamus besar bahasa Indonesia yaitu semangat gotong royong cara Minahasa. Dari dua pengertian diatas maka mapalus merupakan aktivitas atau kegiatan masyarakat untuk saling melengkapi satu dengan yang lain dengan cara saling membantu atau bergotong royong. Mapalus juga dapat diartikan sebagai keterpanggilan masyarakat untuk dapat saling memberdayakan demi terciptanya kesejahteraan.

Budaya Mapalus memiliki hakekat tentang kebersamaan. Budaya mapalus pun digunakan masyarakat Minahasa ini sebagai suatu bentuk kegiatan pembangunan dalam memenuhi kebutuhan bersama, dan dengan tujuan mendapat keuntungan bersama. Dalam penelitian kuantitatif di Desa Tombasian Kapubaten Minahasa, didapatkan bahwa budaya Mapalus memilki pengaruh besar bagi pembangunan kesejahteraan desa (Lumantow, 2017).

Di zaman modern ini, budaya Mapalus, sudah mulai tergeser. Hal itu bisa dilihat dari minimnya pemahaman generasi mudah terhadap budaya Mapalus. Kebanyakan generasi mudah lebih mengikuti budaya-budaya luar dari pada budaya lokal (Salaki, 2014).

Peneliti tertarik melihat budaya kerja Minahasa, karena di satu sisi sebagai tempat tinggal peneliti, tetapi di sisi lain juga mempertanyakan, kenapa masyarakat Minahasa (Sulawesi Utara) tidak terlalu tertarik dengan pemberdayaan ekonomi, terlebih khusus tentang kewirausahaan? Menurut Richard Siwu seorang teolog dan sosiolog kultural, dalam penelitiannya, dia 
melihat bahwa kebanyakan generasi mudah di Sulawesi Utara, terlebih khusus di Minahasa lebih sering menjadi pegawai kantor dari pada terjun ke dalam kewirausahaan. Menurut dia, mentalitas orang Minahasa telah dibentuk oleh mentalitas pegawai. Pertanyaan lain yang muncul, apakah budaya etos kerja minahasa mendukung pemberdayaan ekonomi (kewirausahaan) dan mendukung semangat kapitalisme? Kewirausahaan (enterpeneurship) adalah fenomena baru bagi masyarakat di Minahasa. Walaupun orang Minahasa dulu telah mengetahui sistem barter dan jual-beli, namun wirausaha, yang didalamnya terkandung profit dan nilai tambah, masih merupakan hal yang baru. Wirausaha modern selalu ditandai dengan semangat dagang, dan dimotivasi oleh semangat kapitalisme. Enterpeneurship adalah salah satu pekerjaan masyarakat modern dan juga menjadi salah satu apa yang sosiolog katakan sebagai juxtaposition atau penjajaran modernitas, modernitas berkaitan dengan lima komponen, yaitu kerja, waktu, alam, hidup dan sesama (Siwu, 2002).

Etos kerja masyarakat Minahasa mencerminkan gaya hidup masyarakat Minahasa pada zaman dulu. Di mana mereka lebih bersifat komunal, selalu bersifat penyamarataan antara individu satu dengan yang lainnya. Dalam melakukan suatu pekerjaan, orientasi awal hanya untuk mencari makan, dan bukan untuk kesuksesan. Oleh sebab itu budaya atau etos kerja Minahasa berbeda dengan semangat kapitalisme yang disuarakan oleh Max Weber. Etos kerja Minahasa memliki perbedaan dengan etos kerja Kristen tentang calling, "kewajiban religius", kerja profesional, dan bekerja secara jujur tanpa menjatuhkan orang lain.

\section{SIMPULAN}

Etos kerja Minahasa berbeda dengan etos kerja yang dimiliki oleh Protestan. Etos kerja yang dimiliki oleh Minahasa sangat positif, dimana dalam setiap pekerjaan, selalu berbagi dan saling menolong satu sama lain, dan budaya Mapalus sangat diperlukan juga sebagai identitas masyarakat Minahasa. Di zaman modern saat ini, agar supaya gereja di Minahasa tidak ketinggalan kemajuan yang ada, mau tidak mau warga gereja harus terjun ke dalam kewirausahaan sebagai tindakan nyata dari pemberdayaan ekonomi. Gereja di Minahasa kiranya bisa merekonstruksi kembali nilai budaya Mapalus yang menunjang masyarakat untuk melakukan kewirausahaan yang positif. Oleh sebab itu warga gereja di Minahasa juga harus melakukan "inovasi" yang baru, yakni menciptakan dan mencari kemungkinankemungkinan yang memiliki daya saing, karena tantangan hidup di zaman modern bersifat sosiologis ekonomis yang sifatnya global.

Warga gereja di Minahasa dapat terjun ke dalam kewirausahaan, pertamatama yang harus dilakukan, yaitu mengubah perspektif masyarakat tentang ekonomi dan agama sebagai dua hal yang tidak dapat disatukan. Ketika hal itu terjadi, maka agama dapat mempengaruhi ekonomi. Kemudian yang membantu semangat kapitalisme yang positif itu berasal dari etika Protestan dan nilai budaya Mapalus. Etos kerja Minahasa seperti Mapalus harus direkonstruksi kembali, agar supaya etos kerja Minahasa menjadi sangat penting dalam membantu kewirausahaan yang positif di Minahasa. Di sisi lain, semangat kapitalisme modern yang didukung dan dikontrol oleh etika Protestan - etos kerja Kristen - sangat penting dimiliki oleh setiap warga gereja, agar supaya terwujudnya pemberdayaan ekonomi. Oleh sebab itu etos kerja Minahasa, etos kerja Protestan, dan sikap semangat kapitalisme modern harus seimbang atau balance.

\section{DAFTAR PUSTAKA}

Dillard, D dan Raharjo, M.D. (1987). Kapitalisme Dulu dan Sekarang. Jakarta: LEP3ES. 
Feldy Lolangion, Etos Kerja Kristen dan Budaya Mapalus sebagai Perberdayaan Ekonomi Gereja di

Doyle, P.J., (1986). Teori Sosiologi: Klasik dan Modern. Jakarta: PT Gramedia.

Duchrow, U, (1998). Mengubah Kapitakisme Dunia; Tinjauan Sejarah-Alkirabiah Bagi Aksi Politis. Jakarta: BPK Gunung Mulia.

Haryanto, S, (2015). Sosiologi Agama: Dari Klasik Hingga Postmodern. Yogyakarta: AR-RUZZ Media.

Jones, P, (2009). Pengantar Teori-Teori Sosial: dari Teori Fungsionalisme hingga Postmodernisme. Jakarta: Yayasan Obor Indonesia.

Kalean, H, (2012). Metode Penelitian Kualitatif Interdisipliner bidang Sosial, Budaya, Filsafat, Seni, Agama dan Humaniora. Yogyakarta: Paradigma.

Kristeva, S., dan Sayyid, N., (2015). Kapitalisme, Negara dan Masyarakat. Jogyakarta: Pustaka Pelajar.

Lekacham, R., (2008). Kapitalisme: Teori dan Sejarah Perkembangannya. Yogyakarta: Resist Book.

Lumantow, M., Tampi, G., dan Londa, V., (2017). "Pengaruh Budaya Mapalus Terhadap Partisipasi Masyarakat Dalam Pembangunan di Desa Tombasian Atas Kecamatan Kawangkoan Barat Kabupaten Minahasa." Universitas Sam Ratulangi Manado: Jurnal Administrasi Pubik, 3 (46): 1-18. Diunduh di https://ejournal.unsrat.ac.id/index.php/JAP /article/view/16291/15794/ tanggal 26 Februari 2021
Salaki, R.J,, (2014). “Membangun Karakter Generasi Muda Melalui Budaya Mapalus Suku Minahasa." Universitas Negeri Manado: Jurnal Studi Sosial, 6 (1): 47-52. Diunduh di http://lp2m.um.ac.id/wpcontent/uploads/2014/03/8.pdf/ tanggal 26 Februari 2021.

Sinamo, J., dan Siadari, E.E., (2011). Teologi Kerja Modern dan Etos Kerja Kristiani. Jakarta: Institut Darma Mahardika.

Siwu, R., (2002). Falsafah Minahasa dalam Keindonesiaan. Manado: LETAK.

Soekanto, S., (2009). Sosiologi Suatu Pengantar. Jakarta: Rajawali Pers.

Sugiyono, (2012). Metode Penelitian Kuantitatif Kualitatif dan R\&D. Bandung: Alfabeta.

Sukirno, S., (1985). Ekonomi Pembangunan, Proses, Masalah dan Dasar Kebijaksanaan. Jakarta: Lembaga Penerbit FE UI.

Tinggogoi, J., (2016). Tumou Tou: Hidup Menjadi Manusia Sejati Seutunya. Manado: Percikan Hati.

Tormey, S., (2016). Anti-Kapitalisme: Panduan Bagi Pemula. Makassar: Penerbit Angin.

Turang, J, 1983). Mapalus di Minahasa. Posko Operasi Mandiri Tingkat Dua Kabupaten Minahasa.

Weber, M., (2012). Sosiologi Agama: A Handbook. Jogjakarta: IRCiSoD.

Weber, M., (2015). Etika Protestan dan Semangat Kapitalisme. Jogyakarta: Narasi-Pustaka Promethea. 